\title{
FLORA DE GRÃO-MOGOL, MINAS GERAIS: LYTHRACEAE ${ }^{1}$
}

\author{
TACIANA BARBOSA CAVALCANTI
}

\begin{abstract}
EMBRAPA Recursos Genéticos e Biotecnologia, Parque Estação Biológica, Final W5 Norte, Caixa Postal 02372,
\end{abstract} 70770-900 - Brasília, DF, Brasil

Cavalcanti, T.B. 1989. Cuphea rubro-tirens T. Cav., nova espécie de Minas Gerais, Brasil, e nota sobre C. teleandra Lourteig. Bol. Bot. Univ. Sào Paulo 11: 71-76.

Cavalcanti, T.B. 1995. Revisão de Diplusodon Pohl (Lythraceae). Tese de doutorado, Universidade de São Paulo. São Paulo.

De Candolle, A.P. 1828. Lythrarieae. In A.P. De Candolle (ed.) Prodromus systematics naturalis regni vegetabilis. Treuttel \& Würtz. Paris, vol. 3, p. 75-94.

Graham, S.A. \& Cavalcanti, T.B. 1999. The yellow-flowered species of Cuphea (Lythraceae), including three new taxa. Brittonia 51(1): 24-30.

Graham, S.A. \& Cavalcanti, T.B. 1999. A new yellow-flowered species of Cuphea (Lythraceae) from Bolivia. Brittonia $51(3): 303-306$.

Koemne, B.A.E. 1877. Lythraceae. In C.F.P. Martius \& A.G. Eichler (eds.) Flora brasiliensis. Frid. Fleischer. Leipzig, vol. 13, pars 2, p. 185-370, tab. 39-67.

Koenne, B.A.E. 1903. Lythraceae. In H.G.A. Engler (ed.) Das Pflanzenreich. Wilhelm Engelmann. Berlin, vol. 4, pt. 216: $1-326$.

Lourteig, A. 1987. Lythraceae austroamericanae. Addenda et corrigenda II. Sellowia 39: 5-48.

LourTeig, A. 1989. Lythraceae austroamericanae. Addenda et corrigenda III. Bradea 5(19): 205-241.

1. Ervas a subarbustos de ramificação alterna. Flores zigomorfas, tubo floral estreito e alongado com cálcar na base; ovário com glândula bem desenvolvida na base Cuphea

2. Tubo floral 1,5-2 cm compr., creme-esverdeado com o ápice vermelho a vináceo; os 2 estames dorsais inseridos na metade do tubo floral ou mais abaixo, afastados dos 9 ventrais; pétalas vermelho-carmim. Folhas com margem crenada, um tricoma glandular entre cada crena .....

.. C. teleandra

2'. Tubo floral 0,5-1 cm compr., esverdeado, atropurpúreo ou amarelado com dorso vináceo; os 2 estames dorsais inseridos no terço superior do tubo floral, próximo aos 9 ventrais; pétalas alvas, amarelas, rosa-claro a rosa-magenta, lilases a arroxeadas. Folhas não crenadas.

3. Folhas linear-lanceoladas, hifódromas, 0,5-1 mm larg. Flores concentradas no ápice dos ramos, tubo floral freqüentemente todo atropurpúreo

3'. Folhas lanceoladas a oblongo-lanceoladas, broquidódromas, 3-20 $\mathrm{mm}$ larg. Flores dispostas

ao longo dos ramos, tubo floral quando violáceo, apenas na região dorsal.

4. Flores com pedicelo de $8-20 \mathrm{~mm}$ compr., vesículas infra-estaminais conspícuas.

C. hyssopoides

4'. Flores com pedicelo de 1-5 mm compr., vesículas infra-estaminais ausentes.

5. Folhas pecioladas, pecíolo 3-7 mm compr. Pétalas persistentes no fruto e enroladas para dentro do tubo. Planta muito viscosa

C. lutescens

5'. Folhas sésseis a subsésseis, pecíolo 0-1 $\mathrm{mm}$ compr. Pétalas decíduas. Planta sem viscosidade ou pouco viscosa.

6. Pétalas amarelas C. brachiata

6'. Pétalas lilases, roxas, róseas, rosa-magenta.

7. Folhas de base aguda, elípticas C. micrantha

7'. Folhas de base obtusa a subcordada, lanceoladas C. antisiphylitica

\footnotetext{
${ }^{1}$ Trabalho realizado conforme o planejamento apresentado por Pirani $e$ l al. (2003). Bol. Bot. Univ. São Paulo 21(1): 1-24.
} 
1'. Subarbustos, arbustos ou arvoretas de ramificação oposta. Flores actinomorfas; tubo floral campanulado, desprovido de cálcar na base; ovário sem glândula basal.

8. Flores 8-12-meras, corola branca. Folhas com glândula conspícua no ápice Lafoensia pacari

8'. Flores 6-meras, corola rosa-claro ou rosa-magenta a arroxeadas. Folhas sem glândula no ápice ... Diplusodon

9. Flores com pedicelo de 5-7 mm compr.; estames (16-) 18. Folhas estreitamente elípticas a linear-lanceoladas

D. epilobioides

9'. Flores sésseis a subsésseis; estames 12. Folhas elípticas, ovais, oval-lanceoladas, lanceoladas, obovais a orbiculares.

10. Folhas sésseis, lanceoladas a oval-lanceoladas, margem fortemente revoluta, cobertas por tricomas estrelados, principalmente na face abaxial ................ D. helianthemifolius var. pemphoides

$10^{\prime}$. Folhas pecioladas, pecíolo $2-5 \mathrm{~mm}$ compr., ovais, obovais a orbiculares, cobertas por indumento não estrelado margem plana a levemente revoluta.

11. Folhas orbiculares, cobertas por denso indumento, base obtusa, raro aguda, 4-5 pares de nervuras laterais, folhas dispostas ao longo dos ramos D. hirsutus

11'. Folhas ovais, obovais a elípticas, cobertas por indumento pubescente escasso, base aguda a atenuada, 2-3 pares de nervuras laterais, folhas mais concentradas no ápi-

\section{Cuphea P. Browne}

Subarbustos a ervas, tricomas tectores e glandulares em toda a planta, ramos alternos. Folhas decussadas a 3-5 verticiladas, nervação broquidódroma a hifódroma. Flores solitárias, raro em grupos, hexâmeras, zigomorfas, alternas; profilos 2; tubo floral alongado, cilíndrico, persistente no fruto, 12 costado, calcarado na base; segmentos do epicálice 6, sépalas 6; corola zigomorfa, com 2 pétalas dorsais geralmente de tamanho diferente das ventrais, rosa-magenta, rosa-claro, amarelas, vermelhas ou alvas, decíduas ou persistentes no fruto; estames 11, raro 9 ou 6 , raríssimo 4 ou ausentes, vesículas infra-estaminais às vezes presentes, anteras dorsifixas, versáteis; gineceu bicarpelar, unilocular, ovário geralmente oblongo, disco glandular dorsal ou cupuliforme na base; placenta cilíndrica, crassa, bifurcada no ápice, com as 2 extremidades unidas às paredes do carpelo, estilete filiforme. Fruto cápsula esculicida, abrindo-se por fenda longitudinal por onde irrompe a placenta que toma a posição reflexa e libera as sementes. Sementes arredondadas, elípticas, lenticulares, margem obtusa, espessada ou não ou levemente alada, testa coriácea com região da rafe marcada; na germinação com projeções epidérmicas espiraladas.

1.1. Cuphea antisyphilitica Kunth in Humb., Bonpl. \& Kunth, Nov. gen. sp. 6: 202. 1823.

Subarbusto ca. $40 \mathrm{~cm}$ alt., ramos escabros com tricomas glandulares. Folhas decussadas, broquidódromas, oblongo-lanceoladas, a lanceoladas, , 7-2,5 cm compr., 3-6 mm larg., ápice agudo a raramente obtuso, margem plana a levemente subrevoluta, subcoriáceas, (sub)sésseis, escabras, lâminas cobertas por tricomas apressos e escassos. Flores solitárias, pedicelo ca. $2 \mathrm{~mm}$ compr.; tubo floral pardacento, ca. $8 \mathrm{~mm}$ compr., viscoso, com tricomas glandulares e tectores, cálcar levemente deflexo; pétalas 6 , rosa-magenta; ovário com glândula dorsal deflexa; estames e estilete inclusos, óvulos 3. Sementes 2-3.

\section{Mello-Silva E Pirani CFCR 10848-A (SPF).}

Em Grão-Mogol, Cuphea antisyphilitica foi encontrada em campo graminoso com ervas invasoras, formando pasto próximo à nascente do ribeirão das Mortes, no alto da serra, entre 1100 e $1150 \mathrm{~m}$ s.n.m.
1.2. Cuphea brachiata Koehne in Mart. \& Eichler, Fl. bras. 13(2): 293; tab. 53, fig. 2. 1877.

Subarbusto ca. $50 \mathrm{~cm}$ alt., raro semiprostrado, ramos hirsutos, viscosos, com tricomas glandulares longos. Folhas 3-5 verticiladas, raro decussadas, broquidódromas, lanceoladas a oblongo-lanceoladas, 5-7 mm compr., 3-5 $\mathrm{mm}$ larg., ápice agudo, margem plana a sub-revoluta, base obtusa a subcordada, membranáceas a subcoriáceas, sésseis, escabras, lâminas com tricomas apressos e tricomas longos conspícuos, nervuras inconspícuas. Flores solitárias, pedicelo 2-2,5 mm compr.; tubo floral 5-6 $\mathrm{mm}$ compr., esverdeado, externamente quase glabro e com tricomas glandulares, internamente com indumento laxo, cálcar deflexo; pétalas amarelas, decíduas no fruto; ovário com glândula dorsal bastante deflexa, estames inclusos, estilete exserto, óvulos $3(-5)$. Sementes 2-3. (Fig. 1. A-B)

Cavalcanti et al. CFCR 9682 (SPF); Hensold et al. CFCR 
3569 (SPF); Pirani et al. CFCR 8873 (SPF), CFCR 12533 (CEN, SPF).

Cadeia do Espinhaço, em Minas Gerais e na Bahia; na Bahia e em Alagoas, é encontrada também na restinga. Em Grão-Mogol, foi encontrada no vale do rio Itacambiruçu, em solo arenoso fino às margens do rio, $\mathrm{e}$ em ambiente de cerrado, a ca. $650 \mathrm{~m}$ s.n.m. Floresce no mês de dezembro.

1.3. Cuphea ericoides Cham. \& Schltdl., Linnaea 2: 366. 1827.

Subarbusto 0,4-1,5 $\mathrm{m}$ alt., ramos pubescentes. Folhas 3-5 verticiladas, coriáceas, hifódromas, sésseis, escabras, linear-lanceoladas, ápice agudo, 3-10 mm compr., 0,5-1 $\mathrm{mm}$ larg. Flores geralmente em grupos no ápice dos ramos, pedicelo 2-5 $\mathrm{mm}$ compr.; tubo floral freqüentemente atropurpúreo, às vezes esverdeado, viscoso, externamente pubérulo, com tricomas glandulares, internamente pubescente, cálcar deflexo; pétalas rosamagenta, decíduas no fruto; ovário com glândula dorsal bastante deflexa, estilete exserto, óvulos 3. Sementes 23. (Fig. 1. G-H)

Cavalcanti et al. CFCR 8339, CFCR 9669 (SPF); Cordeiro et al. CFCR 8842 (SPF); Furlan et al. CFCR 706 (SPF); Giulietti et al. CFCR 3563 (SPF); Hatschbach 41378 (MBM, SPF); Hensold et al. CFCR 3490 (SPF); Wanderley 1429 E Kral 75433 (SP, SPF).

Freqüente nos campos rupestres da Cadeia do Espinhaço, em Minas Gerais e na Bahia; ocorre também em Goiás, nos campos rupestres da Serra Geral do Paraná, embora seja menos freqüente neste estado. Em Grão-Mogol, está representada por C. ericoides var. ericoides, e foi encontrada habitando áreas de campo rupestre com afloramentos rochosos e em cerrado. Floresce de novembro a abril.

1.4. Cuphea hyssopoides A. St.-Hil., Fl. Bras. merid. 3: 114. 1833.

Subarbusto até $0,5 \mathrm{~m}$ alt., pouco ramificado, ramos cobertos por tricomas curtos e alvos e tricomas longos e glandulares, quase hirsutos no ápice. Folhas decussadas, nítidas, broquidódromas, sésseis, escabras, lanceoladas, ápice agudo, margem sub-revoluta, com longos tricomas glandulares, base subcordada, 1-2,2 cm compr., 0,5-1,4 $\mathrm{cm}$ larg. Flores solitárias, pedicelo com tricomas longos, 0,8-1,7 cm compr.; tubo floral 0,7-1 cm compr., esverdeado, dorso vináceo, externamente coberto por tricomas longos, glandulares ou não, viloso internamente e geralmente com vesículas infra-estaminais na região da in- serção dos estames, glabro abaixo dos estames, cálcar conspícuo, deflexo; pétalas lilases a arroxeadas, decíduas no fruto; ovário com glândula deflexa, estilete freqüentemente incluso, glabro, óvulos 7-11. Semente ca. 4. (Fig. 1. I-J)

Cavalcanti et al. 281 (CEN, SPF), CFCR 9588 (CEN, SPF, UEC); CFCR 9647 (CEN, SPF); Cordeiro EO MelloSilva CFCR 10036 (SPF); Meguro et al. CFCR 9064 (CEN, SPF); Stannard et al. CFCR 6544 (CEN, K, SPF).

Minas Gerais, em campos-rupestres de 800-1000 m s.n.m. Floresce e frutifica nos meses de fevereiro e março.

1.5. Cuphea lutescens Koehne in Mart. \& Eichler, Fl. bras. 13(2): 299; tab. 55, fig. 2. 1877.

Subarbusto muito viscoso, 0,4-1 $\mathrm{m}$ alt., ramos e folhas cobertos por tricomas glandulosos. Folhas decussadas, membranáceas a subcoriáceas, broquidódromas, pecioladas, lanceoladas, ápice agudo, margem sub-revoluta, base obtusa, lâminas pubescentes com tricomas glandulares, 1,3-5,5 cm compr., 0,6-2 cm larg.; pecíolo 3-7 mm compr. Flores solitárias, pedicelo 2-2,5 mm compr.; tubo floral 0,8-1 cm compr., amarelado, dorso com mancha vinácea, com tricomas glandulares externamente, viloso internamente na região dos estames e abaixo destes, cálcar deflexo; pétalas alvas a lilás-claras, raro róseas, persistentes no fruto; ovário com glândula horizontal, estilete exserto quase glabro, óvulos 3. Sementes 1-2. (Fig. 1. C-D)

Barreto et al. CFCR 12014 (SPF); Cavalcanti et al. CFCR 8300, CFCR 8463 (SPF), CFCR 9594 (SPF, UEC); Furlan. et al. CFCR 770 (SPF); Pirani et al. CFCR 12506 (SPF); Sano et al. CFCR 12406 (CEN, SPF); Simão-Bianchini et al. CFCR 13000 (SPF).

Bahia, Goiás, Minas Gerais, São Paulo, Rio Grande do Sul e Santa Catarina. Em Grão-Mogol, cresce nos solos arenosos em vegetação de carrascal, entre arvoretas e arbustos, aos 750-1200 m s.n.m. Floresce de fevereiro a maio e frutos são observados de setembro a dezembro.

1.6. Cuphea micrantha Kunth in Humb., Bonpl. \& Kunth, Nov. gen. sp. 6: 196. 1823.

Subarbusto ca. $30 \mathrm{~cm}$ alt. pouco ramificado, ramos com tricomas glandulares alvos, estrigosos, quase hirsutos. Folhas decussadas, sésseis a subsésseis, broquidódomas, oblongo-lanceoladas, ápice agudo, base cuneada, 1-3,5 cm compr., 0,6-1 cm larg. Flores solitárias, pedicelo 1-3 mm compr.; tubo floral esverdeado, dorso com pequena mancha vinácea, $5-7 \mathrm{~mm}$ compr., externamente 

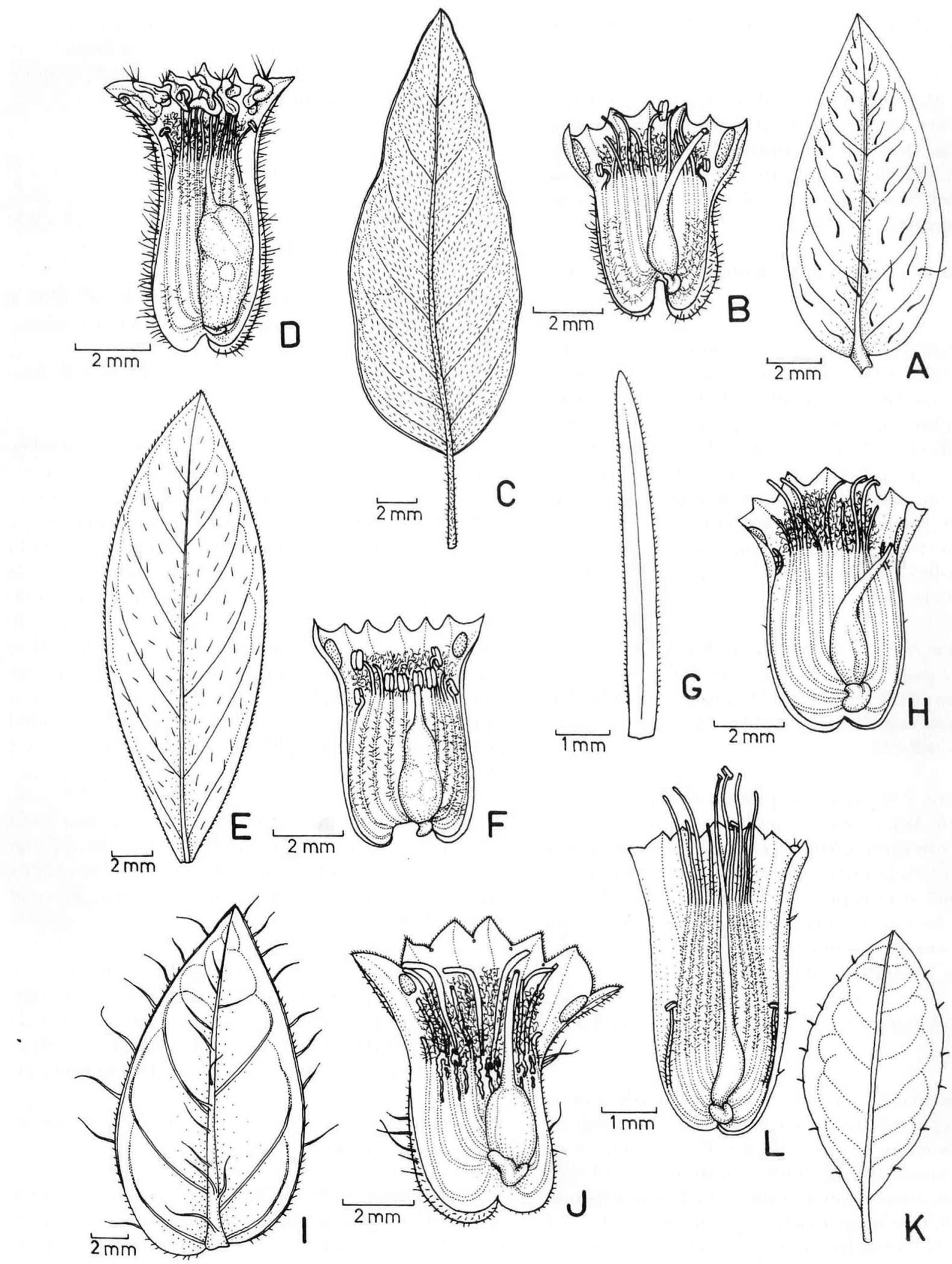

Fig. 1. LYTHRACEAE. Cuphea. A-B. C. brachiata: A. Folha, face abaxial; B. Flor, corte longitudinal-dorsal. C-D. C. lutescens: C. Folha, face abaxial; D. Flor, corte longitudinal-dorsal. E-F. C. micrantha: E. Folha, face abaxial; F. Flor, corte longitudinal-dorsal. G-H. C. ericoides: G. Folha, face adaxial; H. Flor, corte longitudinal-dorsal. I-J. Cuphea hyssopoides: I. Folha, face abaxial; J. Flor, corte longitudinal-dorsal. L-M. C. teleandra: L. Folha, face abaxial; M. Flor, corte longitudinal-dorsal. 
com tricomas esparsos, viloso internamente na região sob os estames e com poucos tricomas na região abaixo da inserção dos estames, cálcar muito pequeno; pétalas lilases a arroxeadas, decíduas no fruto, ovário com glândula deflexa, estilete incluso, glabro, óvulos 3. Sementes 3. (Fig. 1. E-F)

\section{Kameyama et al. CFCR 8850 (SPF).}

Minas Gerais, Bahia, Goiás e Piauí. Espécie ruderal encontrada em Grão-Mogol em áreas perturbadas próximo a estrada.

\subsection{Cuphea teleandra Lourteig, Sellowia 39: 5-48. 1987.}

Subarbusto pouco viscoso, até $2 \mathrm{~m}$ alt., ramos pubérulos. Folhas verticiladas a decussadas, coriáceas, broquidódromas, pecioladas, escabras, ovais, lâmina glabra, indumento inconspícuo nas nervuras, ápice obtuso, raro levemente acuminado, margem levemente revoluta, cre- nada, com tricomas glandulares conspícuos entre as crenas, base atenuada, 0,4-2 cm compr., 0,4-1 cm larg.; pecíolo 2-3 $\mathrm{mm}$ compr. Flores solitárias, pedicelo pubérulo, $3-4,5 \mathrm{~mm}$ compr.; tubo floral creme-esverdeado com ápice vermelho a vináceo, 1,5-2 cm compr., externamente quase glabro, pubérulo apenas na base, com tricomas glandulares, raro pubescente, pouco viloso internamente, guias de néctar ausentes, estames dorsais inseridos na metade do tubo do hipanto ou abaixo da metade, na região do ovário, cálcar deflexo; pétalas vermelho-rosadas, decíduas no fruto; ovário com glândula horizontal, estilete e estames exsertos, óvulos 3. Sementes 2-3, ápice levemente emarginado. (Fig. 1. L-M)

Cavalcanti et al. CFCR 9618 (SPF); Pirani et al. CFCR 9024 (SPF); Sano et al. CFCR 12846 (CEN, SPF).

Endêmica de Grão-Mogol; em vegetação de campo rupestre, entre 1000 e $1200 \mathrm{~m}$ s.n.m. Floresce em dezembro.

\section{Diplusodon Pohl}

Subarbustos, arbustos até arvoretas, ramos oposto-cruzados, cilíndricos a quadrangulares, alados ou não. Folhas decussadas, hifódromas, eucamptódromas a acródromas. Flores em bótrios simples ou compostos a tirsos, hexâmeras, actinomorfas, opostas; profilos 2; tubo floral campanulado a oblongo, persistente no fruto; corola actinomorfa, rosa-claro, rosa-magenta a roxa, raro alva; androceu diplostêmone, polistêmone a mais raramente haplostêmone, estames 6-43, geralmente exsertos, anteras dorsifixas, versáteis; gineceu bicarpelar, unilocular com septo incompleto, ovário oval-depresso a obcônico, glabro ou mais raramente com tricomas no ápice, placenta basal, na frutificação crassa e com 2 septos semilunares; estilete filiforme, arcado, capitado, exserto. Fruto cápsula septicida, sementes planas a lenciformes, aladas, ala pequena, embrião reto, projeções epidérmicas das sementes retas.

\subsection{Diplusodon aggregatifolius T.B.Cavalc., Novon 8(4):} 337. 1998.

Subarbusto $0,7-1,7 \mathrm{~m}$ alt., ramos com indumento pubescente alvo. Folhas decussadas, concentradas no ápice dos ramos, eucamptódromas, pecioladas, elípticas, a obovais, mais raramente orbiculares, ápice obtuso, margem plana, base aguda a atenuada, $1-3 \mathrm{~cm}$ compr., lâminas com indumento pubescente e alvo, face adaxial com nervuras 2-3 nervuras laterais inconspícuas; pecíolo $3-5 \mathrm{~mm}$ compr. Diplobótrio a pleiobótrio bastante laxo, hipopódio 1-2 mm compr., epipódio até $0,5 \mathrm{~mm}$ compr., profilos alcançando a metade do tubo floral, tubo floral pubescente, segmentos do epicálice patentes a levemente deflexos, 1,5-2,5 mm compr.; corola rosa-magenta; estames 12; óvulos 6-14. Sementes 4-6 por fruto. (Fig. 2. H-I)

Cavalcanti et al. 278 (CEN, SPF), CFCR 9595 (holótipo SPF, isótipos CEN, K, MBM, UEC); Cordeiro et al. CFCR 776, CFCR 9122 (SPF); Furlan et al. CFCR 741 (K, SPF); Giuliettiet al. CFCR 3423 (SPF); Mello-Silza E Pirani CFCR
10763 (CEN, K, SPF); Pirani Eo Mello-Silva CFCR 10811 (K, SPF); Pirani et al. CFCR 904, CFCR 2255 (SPF).

Restrita a Grão-Mogol e Itacambira, habita os campos rupestres com arenito e floresce no início do ano, de fevereiro a maio.

\subsection{Diplusodon epilobioides DC., Prodr. 3: 94. 1828.}

Subarbusto 1-2 m alt., ramos pubérulos, quase glabros. Folhas decussadas, eucamptódromas, linear-lanceoladas a estreitamente elípticas, ápice agudo, margem revoluta, base aguda a atenuada, 0,8-2 cm compr., 2-3 cm larg., lâminas com indumento inconspícuo, 1-2 nervuras laterais, proeminentes na face abaxial, pecíolo ca. $2 \mathrm{~mm}$ compr. Diplobótrio a pleiobótrio, hipopódio 2-3 $\mathrm{mm}$ compr., epipódio 3-4 $\mathrm{mm}$ compr., profilos alcançando a base do tubo floral, tubo floral quase glabro, segmentos do epicálice patentes a suberetos, 1,8-3 mm compr; corola rósea; estames 16(-18); óvulos 10-17. Sementes 5-9 por fruto. (Fig. 2. F-G) 
Cordeiro Ẽ Mello-Silva CFCR 10144 (K, F, P, SPF); Hatschbach Eं Nicolack 54233 (MBM); Kral et al. 72695 (SPF); Lanstryak s.n. (R); Martinelli et al. 11163 (BHCB, NY, RB); Mello-Silva et al. CFCR 9881 (CEN, K, P, SPF); Mendes-Magalhäes 18389 (UB).

Norte da Cadeia do Espinhaço de Minas Gerais, em Cristália e Grão-Mogol e, na Bahia, nos campos rupestres da serra de Caetité. Em Grão-Mogol, ocorre em áreas de carrascal de solo arenoso com canga de hematita, entre 870-1039 m s.n.m., e em cerrado, aos 800 m s.n.m. Floresce de julho a outubro já podendo-se observar frutos de agosto a outubro.

\subsection{Diplusodon helianthemifolius var. pemphoides (DC.)} Koehne in Mart. \& Eichler, Fl. bras. 13(2): 325. 1877.

Subarbusto 0,4-1 m alt., ramos com indumento pubérulo a viloso, canescente a ferrugíneo, composto por tricomas estrelados. Folhas decussadas, eucamptódromas a acródromas, sésseis, lanceoladas a oval-lanceoladas, ápice agudo, margem revoluta, base obtusa a cordada, 0,7-2 cm compr., 0,3-1,3 cm larg., face adaxial geralmente verde-oliva, verrucosa, face abaxial canescente, densamente coberta por tricomas estrelados, 2-3 nervuras laterais, ferrugíneas. Diplobótrio a pleiobótrio, flores subsésseis, profilos superando a metade do tubo floral ou alcançando o ápice do mesmo, tubo floral diminutamente piloso, quase glabro, segmentos do epicálice deflexos a patentes, 1-1,5 $\mathrm{mm}$ compr.; corola rósea a arroxeada; estames 12; óvulos 12-14. Sementes 10-12. (Fig. 2. C-E)

Cavalcanti et al. 282, 285 (CEN, SPF), CFCR 8528, CFCR 9644A, CFCR 9650, CFCR 10175 (SPF); Esteves et al. CFCR 13372 (CEN, SPF); Freire-Fierro et al. CFCR 12730 (SPF); Marcgraf 3426 (SPF); Tenório 79-2147 (CETEC);
Zappi et al. CFCR 12879 (CEN, SPF).

Bahia, Goiás e norte de Minas Gerais, em campo rupestre de areia muito branca, aos $1130 \mathrm{~m}$ s.n.m., entre os 900 e $1000 \mathrm{~m}$ em vegetação ecotonal densa do tipo carrascal e, entre os 700 e $800 \mathrm{~m}$, habita ambientes de cerrado.

2.4. Diplusodon hirsutus (Cham. \& Schltdl.) DC., Prodr. 3: $94 \mathrm{c} .1828$.

Subarbusto 0,9-3 m alt., ramos com indumento denso, canescente. Folhas decussadas, congestas, eucamptódromas a acródromas, pecioladas, orbiculares a oval-elípticas, ápice arredondado, margem plana a subrevoluta, base arredondada a raro aguda, 0,6-2 cm compr., 0,6-1,6 mm larg., lâminas com indumento denso e canescente, 4-5 nervuras laterais; pecíolo $1-3 \mathrm{~mm}$ compr. Pleiobótrio, flores sésseis a subsésseis, profilos alcançando a metade do tubo floral ou até o ápice, tubo floral densamente coberto por tricomas alvos a menos piloso, segmentos do epicálice patentes a pouco deflexos; corola rosa-claro, lilás a arroxeada; estames 12 , óvulos 13-18. Sementes 7-16. (Fig. 2. A-B)

Mello-Silva ${ }^{\circ}$ Pirani CFCR 10761 (CEN, K, SPF); Mamede et al. CFCR 3465 (CEN, K, SPF); Prado et al. CFCR 12013 (CEN, SPF); Tenório 79-2100 (CETEC); Zappi et al. CFCR 9931 (CEN, K, SPF).

Cadeia do Espinhaço, desde o sul de Minas Gerais até Grão-Mogol, reaparecendo na Chapada Diamantina, na Bahia. Em Grão-Mogol, a espécie foi encontrada em vegetação arbustivo-arbórea de carrascal, sobre substrato arenoso, entre 850-900 m s.n.m., no cerrado aos $830 \mathrm{~m}$ s.n.m. e nos campos rupestres. Floresce de maio a julho e já apresenta frutos neste último mês.

\section{Lafoensia Vand.}

Árvores a arvoretas, raro arbustos. Folhas oposto-cruzadas, broquidódromas, nervura coletora conspícua na margem, ápice com glândula proeminente. Racemos frondoso-bracteosos a bracteosos. Flores actinomorfas, opostas, axilares, 8-16 meras, bibracteoladas, bractéolas geralmente caducas antes da antese; tubo floral carnoso, semigloboso, campanulado, urceolado ou subpiriforme, caduco na frutificação, internamente com linha estaminal bem marcada, tecido nectarífero em torno da região basal, epicálice ausente; sépalas iguais entre si; corola branca, creme ou amarelo-claro; estames 12-32; ovário estipitado, unilocular com septo incompleto, liso ou com depressões na região equatorial; placenta basal. Cápsula com deiscência irregular, sementes retangulares, raro redondas, aladas, ala conspícua.

3.1. Lafoensia pacari A.St.-Hil., Fl. Bras. merid. 3: 159. 1833.

Arbusto a arvoreta, totalmente glabros, ca. $3 \mathrm{~m}$ alt.
Folhas decussadas, coriáceas, nítidas na face adaxial, obovais a oblongo-elípticas, ápice obtuso com acúmen largo, emarginado e reflexo, margem subrevoluta, base atenuada a obtusa, 5-9 cm compr., 1,5-3 cm larg.; pecíolo 

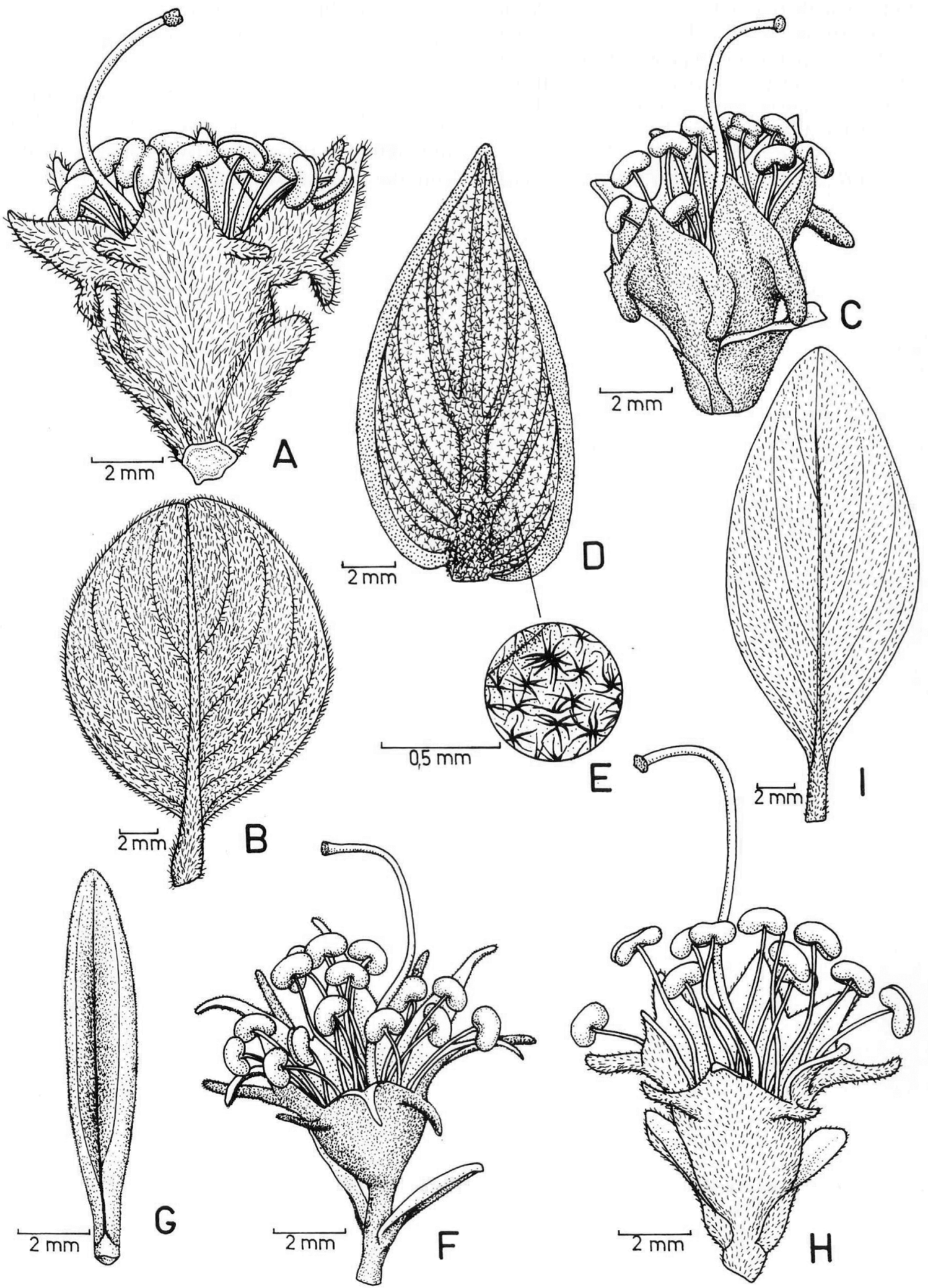

Fig. 2. LYTHRACEAE. Diplusodon. A-B. 1) hirsulus: A. Flor, removidas as pétalas; B. Folha, face abaxial. C-E. D. helianthemifolius var. pemphoides: C. Flor, removidas as pétalas; D. Folha, face abaxial; E. Indumento em detalhe. F-G. D. epilobioides: F. Flor, removidas as pétalas; G. Folha, face adaxial. H-I. D. aggregatifolius: H. Flor, removidas as pétalas; I. Folha, face adaxial. 
5-7 mm compr., canaliculado. Flores 2-9, mais concentradas no ápice dos ramos, tubo floral verde a vináceo, 2-2,5 cm compr., campanulado, sépalas 8 , reflexas, caudadas. Fruto liso, oboval-globoso, ca. $3,5 \mathrm{~cm}$ compr., ca. $2 \mathrm{~cm}$ larg., sementes aladas, oblongas com extremidades retusas, ca. 2,5 cm compr., ca. $1 \mathrm{~cm}$ larg.

Assis et al. CFCR 11356 (CEN, SPF); Cordeiro et al. CFCR
996 (CEN, SPF); Pirani Ẽ Mello-Silva CFCR 10756 (CEN, SPF); Zappi et al. CFCR 9902 (CEN, SPF).

Em Grão-Mogol, ocorre em cerrados, em altitudes de 750-830 m, em vegetação arbustivo-arbórea, freqüentemente perto de cursos d'água. Foi encontrada com flores em abril e maio e com frutos em novembro. 